\title{
FOTOSSÍNTESE E TOLERÂNCIA PROTOPLASMÁTICA FOLIAR EM Myracrodruon urundeuva FR. ALL.
}

\author{
Kátia Rose Silva Mariano ${ }^{1}$, Lílian Santos Barreto ${ }^{1}$, Alisson Harley Brito da Silva ${ }^{2}$, \\ Graziela Katarina Pereira Neiva ${ }^{3}$, Ailton de Jesus Ribeiro ${ }^{4}$, Solange Maria Costa de Amorim ${ }^{5}$ \\ ${ }^{1}$ Bióloga, M.Sc., Depto. de Ciências Biológicas, UEFS, Feira de Santana, Bahia, Brasil - katiarosesilva@ yahoo.com.br - \\ lbarreto@ufba.br \\ ${ }^{2}$ Biólogo, M.Sc., Depto. de Ciências Biológicas, UEFS, Feira de Santana, Bahia, Brasil - alissonharley@ yahoo.com.br \\ ${ }^{3}$ Bióloga, Depto. de Ciências Biológicas, UEFS, Feira de Santana, Bahia, Brasil \\ ${ }^{4}$ Biólogo, Depto. de Ciências Biológicas, UEFS, Feira de Santana, Bahia, Brasil \\ ${ }^{5}$ Bióloga, Dra ${ }^{\mathrm{a}}$, Depto. de Ciências Biológicas, UEFS, Feira de Santana, Bahia, Brasil - samorim@uefs.br \\ Recebido para publicação: 10/12/2007 - Aceito para publicação: 15/02/2009
}

\begin{abstract}
Resumo
Myracrodruon urundeuva Fr. All., Anacardiaceae conhecida como aroeira-do-sertão, pode ser encontrada na Caatinga, no Cerrado e em Floresta Pluvial. As taxas de fotossíntese e transpiração, condutância estomática, conteúdo relativo de água e a tolerância protoplasmática foliar foram medidos em plantas com cinco meses de idade, sob condições de casa de vegetação, e submetidas a dois regimes de suprimento de água: irrigação diária e nenhum suprimento de água durante cinco dias. As avaliações foram feitas nas folhas das posições apical, intermediária e básica da planta. O déficit da água promoveu o incremento no conteúdo relativo de água nas folhas de todas as posições na planta, assim como a taxa reduzida da fotossíntese. As folhas apicais foram as mais sensíveis aos regimes de suprimento de água. Submetidas a alta temperatura, as folhas da posição intermediária no caule mostraram uma tolerância protoplasmática mais elevada.
\end{abstract}

Palavras chave: Aroeira-do-sertão; déficit hídrico.

\begin{abstract}
Photosynthesis and leaf protoplasmatic tolerance in Myracrodruon urundeuva. The Myracrodruon urundeuva Fr. All. (Anacardiaceae) is known as aroeira-do-sertão and is natural of Caatinga, Cerrado and Atlantic Rain Forest. Photosynthesis and transpiration rates, stomatal conductance, relative water content and leaf protoplasmatic tolerance were measured on five months old plants grown under greenhouse conditions and submitted to two water supply regimes: daily irrigation and no water supply during five days. Evaluations were made in leaves of apical, intermediary and basal position of plant. The water deficit promoted increment in relative water content in leaves of all positions as also reduced photosynthesis rate. The apical leaves were the most sensitive to water supply regimes. At higher temperature the leaves located at intermediary position in stem showed higher protoplasmatic tolerance.
\end{abstract}

Keywords: Aroeira-do-sertão; water deficit.

\section{INTRODUÇÃO}

A espécie Myracrodruon urundeuva Fr. All., conhecida como aroeira-do-sertão, é uma árvore nativa da família Anacardiaceae de ocorrência natural desde o México até a Argentina (BILONI, 1976). Essa planta pode ser encontrada em formações vegetais de Caatinga, Cerrado e Floresta Pluvial (ANDRADE et al., 2000), sendo bastante utilizada como planta medicinal e madeira de lei nas indústrias e propriedades rurais, principalmente na região do semiárido brasileiro (MEDEIROS, 1996). Devido à exploração predatória, essa espécie está ameaçada de extinção, exigindo estudos que garantam sua sobrevivência e viabilizem sua utilização em solos não incorporados ao sistema produtivo da região (MELLONE et al., 2000).

Segundo Larcher (2006), a água é o principal constituinte do vegetal, representando $50 \%$ da massa fresca nas plantas lenhosas e cerca de 80 a 95\% nas plantas herbáceas, sendo necessária para o 
transporte de solutos e gases, como reagente no metabolismo vegetal, na turgescência celular e na abertura dos estômatos. A água é fator limitante para o crescimento e desenvolvimento de plantas em regiões áridas e semiáridas, as quais se caracterizam pela baixa precipitação pluviométrica total e pela irregularidade na distribuição das chuvas durante o ano.

A resposta fisiológica à deficiência hídrica pode chegar a efeitos irreversíveis na estrutura das membranas celulares (SILVA, 1976), devido às alterações na composição da integridade destas (PAULA et al., 1990), causadas, em parte, pelo aumento da atividade de lipases, proteases e formas ativas de oxigênio no citoplasma (ROY-MACAULEY et al., 1992). Uma das consequências nesse estádio é o aumento da permeabilidade celular e a saída de íons da célula (DEXTER et al., 1932). Essa extrusão de íons pode ser avaliada pela medida da condutividade elétrica e, portanto, inferir o grau de tolerância protoplasmática foliar à seca.

Sob condições de déficit hídrico, tem sido demonstrada a relação direta entre a redução da concentração intercelular de $\mathrm{CO}_{2}$, em razão do fechamento estomático, gerando decréscimos na assimilação do $\mathrm{CO}_{2}$, e o rendimento quântico do fotossistema II. Considerando as características dos sítios de ocorrência da aroeira, durante a regeneração natural as plantas jovens estariam sujeitas tanto ao estresse hídrico como a limitações na disponibilidade de luz (PAIM, 2002).

Dessa forma, é presumível que, nos períodos de seca, ocorra grande restrição na transpiração, com decréscimos na atividade fotossintética. Esse fato é relevante para programas de reflorestamento com espécies nativas que visam a recuperação de áreas degradadas, devido ao desaparecimento de espécies florestais comprometer significativamente os estudos genéticos e a formação de bancos de germoplasma (SILVA et al., 2000). O objetivo deste estudo foi avaliar a variação do conteúdo relativo de água, a tolerância protoplasmática foliar à seca e, sobretudo, respostas na fotossíntese, transpiração e condutância estomática em plantas de Myracrodruon urundeuva Fr. All. submetidas ao déficit hídrico.

\section{MATERIAL E MÉTODOS}

O experimento foi realizado em condições de viveiro, com filtragem de $50 \%$ de luminosidade, na unidade experimental do Horto Florestal da Universidade Estadual de Feira de Santana (UEFS), em mudas de Myracrodruon urundeuva (aroeira-do-sertão). As sementes foram obtidas na Empresa Brasileira de Pesquisa Agropecuária, no Centro de Pesquisa Agropecuária do Trópico Semiárido. As plantas foram cultivadas em sacos plásticos com capacidade para dois litros de terra vegetal, segundo Paim (2002).

Este ensaio seguiu o delineamento inteiramente ao acaso, com dois tratamentos (irrigação diária e com déficit hídrico), quatro mudas (repetições) por tratamento e em três posições foliares marcadas no caule de cada muda: basal, intermediária e apical. As avaliações foram feitas em mudas com cinco meses, apresentando a altura média de $26 \mathrm{~cm}$, com diâmetro médio do coleto igual a $3 \mathrm{~mm}$ e número médio de folhas igual a 14. Foram realizadas a análise da variância (ANOVA) bifatorial e da comparação múltipla (Tukey, p <0,05), para verificar as diferenças significativas entre as variáveis estudadas através do programa de estatística Sigmastat, Statistical Software para Windows, versão 2, da Jandel Corporation (1995).

No sexto dia de estresse hídrico por suspensão de rega, nos três pares de folhas localizados nas posições basal, intermediária e apical, foram realizadas as medições das taxas de fotossíntese, transpiração e condutância estomática, mediante a utilização do sistema analisador de fotossíntese (LICOR 6200) na porção mediana de cada folíolo (três por folha), como mostra a figura 1, considerando os valores médios dos parâmetros fisiológicos em cada folha para a submissão à análise estatística acima mencionada.

Para a análise do conteúdo relativo de água (CRA) nos tratamentos experimentais, foram coletados dois discos foliares em posições diferentes do caule (base, intermediária e ápice), totalizando vinte e quatro unidades experimentais, tomando-se o cuidado de não amostrar a nervura central. O CRA foi obtido a partir da fórmula CRA = (MF - MS) / (MT - MS) x 100\%, segundo Barrs; Weatherley (1962), em que MF, MS e MT representam a massa fresca, massa seca e a massa total, respectivamente.

Os discos coletados ( $1 \mathrm{~cm}^{2}$ de área) foram acondicionados em placas de Petri com tampa para pesagem da massa fresca. Em seguida adicionou-se água destilada nas placas, sendo estas colocadas na geladeira por $24 \mathrm{~h}$, com a finalidade de obter a massa túrgida. Para a massa seca, os discos foram submetidos a $60{ }^{\circ} \mathrm{C}$ por $72 \mathrm{~h}$. 

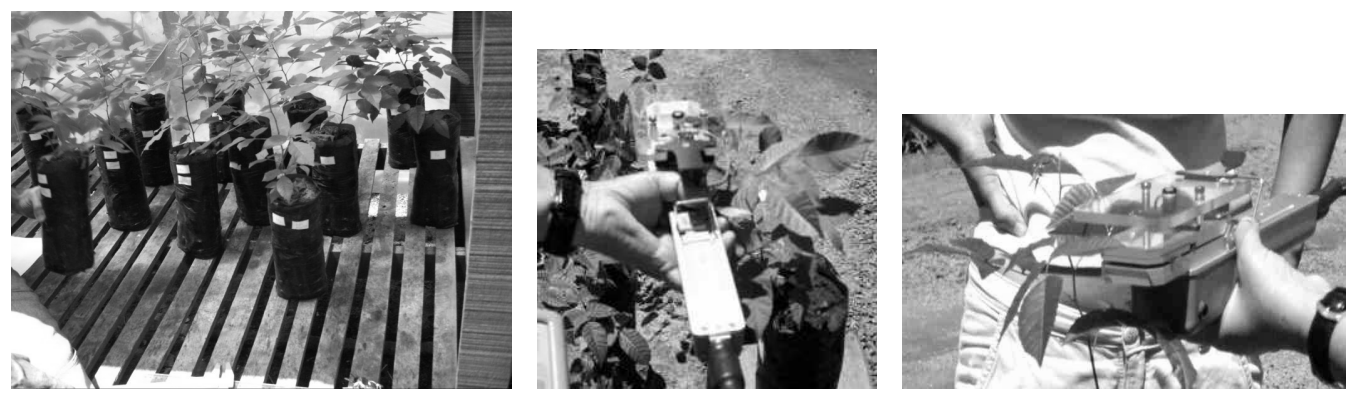

Figura 1. Método de amostragem de transpiração, fotossíntese e condutância estomática em folhas de plantas de Myracrodruon urundeuva irrigadas e sob déficit hídrico durante 5 dias.

Figure 1. Sampling method to estimate the transpiration rate, photosynthesis rate and stomatal conductance in Myracrodruon urundeuva leaves, irrigating and under water deficit during 5 days.

Para avaliação da tolerância protoplasmática do tecido foliar, foram também coletados dois discos foliares em cada posição do caule (base, intermediária e ápice), totalizando vinte e quatro unidades experimentais para cada tratamento experimental. Os discos foram colocados em tubos de ensaio com $30 \mathrm{ml}$ de água destilada e ficaram imersos por $24 \mathrm{~h}$. Após esse período, mediu-se a condutividade livre (CL, $\mu$ Siemens), e posteriormente os mesmos tubos de ensaio foram colocados em geladeira por $1 \mathrm{~h}$ sob temperatura de $4{ }^{\circ} \mathrm{C}$. Após a leitura em condutivímetro (Analion C701), foram levados ao banho-maria a $100{ }^{\circ} \mathrm{C}$ por $1 \mathrm{~h}$, sendo medida a condutividade total (CT, $\mu$ Siemens). A partir desses dados, foram calculadas a porcentagem de integridade absoluta (PIA), sendo PIA $=1-$ CL/CT x 100; a porcentagem de integridade relativa (PIR), sendo PIR = PIA de plantas estressadas / PIA de plantas irrigadas; e a porcentagem de danos (PD), sendo PD = 100 - PIR, segundo a metodologia descrita por Vasquez-Tello et al. (1990).

\section{RESULTADOS E DISCUSSÃO}

A suspensão da irrigação das plantas de aroeira por cinco dias provocou alterações na taxa de fotossíntese $(\mathrm{p}=0,023)$, embora a análise de variância tenha mostrado que o déficit hídrico ocasionou a redução não significativa na taxa de transpiração $(\mathrm{p}=0,802)$ e de condutância estomática $(\mathrm{p}=0,058)$, em relação ao controle.

A posição foliar pareceu interferir nas respostas fisiológicas. Diferenças foram evidenciadas entre as folhas intermediárias e as folhas localizadas na base e ápice $(\mathrm{p}=0,002)($ Tabela 1$)$.

Tabela 1. Transpiração, fotossíntese e condutância estomática em folhas de plantas de Myracrodruon urundeuva, irrigadas e sob déficit hídrico durante 5 dias.

Table 1. Transpiration, photosynthesis e stomatal conductance in Myracrodruon urundeuva, leaves, irrigating and under water deficit during 5 days.

\begin{tabular}{|c|c|c|c|c|}
\hline Tratamento & $\begin{array}{l}\text { Posição foliar } \\
\text { no caule }\end{array}$ & 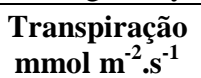 & $\begin{array}{c}\text { Condutância estomática } \\
\mathrm{cm}^{-\mathrm{s}^{-1}}\end{array}$ & $\begin{array}{l}\text { Fotossíntese } \\
\mu \mathrm{mol} \mathrm{m}^{-2} \cdot \mathrm{s}^{-1}\end{array}$ \\
\hline \multirow{3}{*}{ Controle } & base & ${ }^{*} 2,16 \pm 1,89 \mathbf{b} c$ & $0,06 \pm 0,03 \mathbf{b} c$ & $3,17 \pm 1,11 \mathbf{b} c$ \\
\hline & intermediária & $4,93 \pm 1,74 \mathbf{a} c$ & $0,23 \pm 0,10 \mathbf{a} c$ & $6,91 \pm 1,77 \mathbf{a} c$ \\
\hline & ápice & $1,89 \pm 0,29 \mathbf{b} c$ & $0,04 \pm 0,005 \mathbf{b} c$ & $2,74 \pm 0,56 \mathbf{b} c$ \\
\hline \multirow{3}{*}{ Déficit hídrico } & base & $2,04 \pm 1,81 \mathbf{b} c$ & $0,04 \pm 0,05 \mathbf{b} c$ & $1,93 \pm 1,91 \mathbf{b} d$ \\
\hline & intermediária & $4,06 \pm 1,00 \mathbf{a} c$ & $0,10 \pm 0,04 \mathbf{a} c$ & $4,01 \pm 1,26 \mathbf{a} d$ \\
\hline & ápice & $2,46 \pm 1,20 \mathbf{b} c$ & $0,06 \pm 0,04 \mathbf{b} c$ & $2,55 \pm 1,43 \mathbf{b} d$ \\
\hline
\end{tabular}

*Os valores representam as médias e desvios padrões ( \pm ) de 4 repetições. Médias seguidas da mesma letra minúscula em negrito na coluna (comparação de médias entre as posições foliares) e minúscula em itálico (comparação de médias entre os tratamentos) não diferem estatisticamente pelo teste de Tukey a $5 \%$.

Esses resultados assemelharam-se aos encontrados por Silva et al. (2003), em que foram observadas reduções nos valores da transpiração em plantas jovens de Mimosa caesalpinifolia, 
Enterolobium contortisiliquum e Tabebuia aurea, quando submetidas a períodos crescentes de déficit hídrico (5, 7, 13 e 22 dias), embora com variações maiores na taxa de transpiração, de 1,55 a 10,44 mmol $\mathrm{m}^{-2} \cdot \mathrm{s}^{-1}$ para os controles e de 1,03 a $2,99 \mathrm{mmol} \mathrm{m} \mathrm{m}^{-2} \cdot \mathrm{s}^{-1}$ para as estressadas. Em outros experimentos, Mansur; Barbosa (2000) testaram o efeito de 14 dias de suspensão de rega em plantas jovens de Caesalpinia pyramidalis, Caesalpinia ferrea, Senna martiana e Senna spectabilis, mostrando valores reduzidos nas taxas de transpiração, de $0,66,0,65,0,54$ e $0,66 \mu \mathrm{mol} \mathrm{m}{ }^{-2} \cdot \mathrm{s}^{-1}$, respectivamente. Da mesma forma, Nogueira et al. $(1998 ; 1998 ; 1999)$ observaram reduções na transpiração em plantas da Caatinga submetidas ao déficit hídrico.

A redução da transpiração se dá em decorrência do fechamento estomático, que é uma das primeiras respostas da planta à redução da disponibilidade de água. Segundo Larcher (2006), a transpiração e a resistência difusiva (que é inversamente proporcional à condutância estomática) são processos que têm sido correlacionados ao déficit hídrico. Em condições normais, a taxa de transpiração nas folhas é determinada especialmente pela radiação, pelo déficit de saturação e pela condutância estomática.

A suspensão da irrigação levou a uma diminuição da condutância estomática de $0,047 \mathrm{~cm} \cdot \mathrm{s}^{-1}$ $(\mathrm{p}=0,058)$, considerada não significativa na análise de variância. Essa diminuição da condutância estomática também foi observada por Queiroz et al. (2002) em plantas de aroeira submetidas a 14 dias de déficit hídrico, assim como Paim (2002) e Amorim et al. (2004).

Quando foram analisados os valores da condutância estomática nas folhas localizadas nas diferentes posições do caule, a variação assemelhou-se às taxas de transpiração. Valores maiores de condutância estomática foram apresentados nas folhas intermediárias com relação às folhas localizadas na base e no ápice para ambos os tratamentos (Anova, $\mathrm{p}<0,001$ ) (Tabela 1).

Entretanto, o déficit hídrico levou à diminuição significativa de $1,443 \mu \mathrm{mol} \mathrm{m} \mathrm{m}^{-2} \cdot \mathrm{s}^{-1}$ na taxa fotossintética (Anova, $\mathrm{p}=0,023$ ), e essa redução também foi observada por Queiroz et al. (2002) em plantas de aroeira do sertão submetidas a déficit hídrico.

Os valores da transpiração mostraram relação direta com a condutância estomática e com a fotossíntese. Os dados obtidos no presente trabalho sugerem que o fechamento dos estômatos, durante a suspensão da irrigação, ocasionou uma diminuição na condutância estomática, que resultou numa menor difusão do $\mathrm{CO}_{2}$ para o interior das folhas e consequentemente na redução da fotossíntese.

Quanto à idade das folhas, houve diferença na transpiração e condutância estomática, sendo maiores nas folhas intermediárias do que nas folhas do ápice e da base nos dois tratamentos de irrigação. Esse resultado pode ser atribuído ao crescimento das folhas intermediárias, que estão completamente estendidas, o que torna a amplitude de resposta dos estômatos mais efetiva. As folhas do ápice, além de não estarem completamente estendidas, apresentam células imaturas (em crescimento). As folhas da base, as mais velhas, apresentam-se com estômatos mais vulneráveis à situação de estresse.

Houve diminuição na taxa fotossintética entre as diferentes posições das folhas ao longo do vegetal. Nogueira et al. (2001), trabalhando com acerola, observaram maiores valores da taxa de fotossíntese nas folhas em comparação com as folhas jovens. Os resultados obtidos neste experimento com aroeira corroboram a teoria da "longevidade ótima" da folha (KIKUZAWA, 1991): as taxas fotossintéticas foram menores nas do ápice, em folhas que não desenvolveram completamente os mecanismos de fotossíntese. Segundo Kitajima et al. (2002), esse declínio não é um descontrolado mecanismo de deterioração fisiológica, mas um mecanismo de redistribuição de recursos, especialmente de nitrogênio, em folhas jovens para favorecer do ganho fotossintético.

A condutância estomática foi maior nas folhas intermediárias do que nas folhas do ápice e da base, concordando com os resultados obtidos para os valores da fotossíntese e da transpiração, uma vez que a condutância governa diretamente a transpiração e indiretamente a fotossíntese.

A análise de variância $(\mathrm{p}=0,029)$ mostrou que as plantas submetidas a irrigação diária apresentaram um maior conteúdo relativo de água $(85 \%)$ do que as plantas submetidas ao déficit hídrico (48\%). Essas diferenças assemelharam-se aos resultados encontrados por Queiroz (2002) em trabalho realizado com a mesma espécie de aroeira, no qual foram obtidos valores maiores de conteúdo relativo de água nas plantas irrigadas diariamente do que nas plantas estressadas por 14 dias.

Com relação à posição das folhas, o conteúdo relativo de água foi maior nas folhas localizada na base $(41 \%)$ e no ápice (93\%) nas plantas irrigadas diariamente (controle), enquanto que nas plantas 
submetidas ao déficit hídrico o conteúdo relativo de água foi maior nas folhas intermediárias (97\%) e do ápice (100\%) e menor nas folhas localizadas na posição base (59\%), conforme mostra a figura 2.

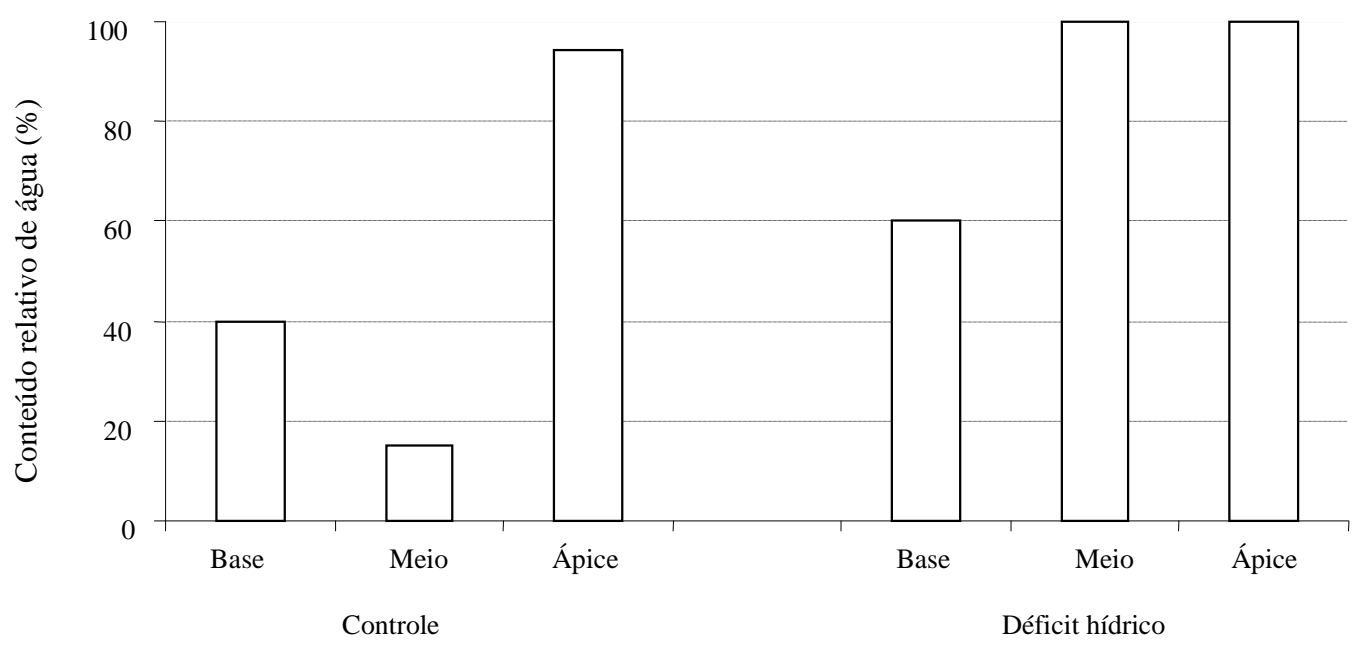

Figura 2. Conteúdo relativo de água (CRA) em mudas de Myracrodruon urundeuva Fr. All. em dois tratamentos, irrigadas e sob déficit hídrico durante 5 dias.

Figure 2. Relative water content (RWC) in Myracrodruon urundeuva Fr. All. plants under two treatments, irrigating and under water deficit during 5 days.

Os resultados relacionados ao conteúdo relativo de água mostraram que as reduções da transpiração e da condutância estomática afetaram o estado hídrico das folhas nas diferentes posições do caule, principalmente nas folhas intermediárias.

A porcentagem de integridade absoluta (PIA) apresentou seus maiores valores para a temperatura de $100{ }^{\circ} \mathrm{C}$, em ambos os tratamentos: controle e déficit hídrico. As folhas mais velhas (folhas basais) apresentaram valores de PIA iguais a $82 \%$ e $85 \%$, respectivamente, e valores de PIA reduzidos para a temperatura de $4{ }^{\circ} \mathrm{C}$, em particular para as folhas intermediárias e basais, iguais a $34 \%$ e $20 \%$, respectivamente.

As folhas intermediárias e basais, quando foram submetidas à temperatura de $100{ }^{\circ} \mathrm{C}$, apresentaram valores de PIA de $77 \%$ e $80 \%$, respectivamente, para o tratamento com irrigação diária, e $82 \%$ e $58 \%$ para o tratamento com déficit hídrico.

O percentual de integração relativo (PIR) nas folhas intermediárias e basais foi menor (93\% e 96\%, respectivamente) a $100{ }^{\circ} \mathrm{C}$ quando comparado com o valor de PIR a $4{ }^{\circ} \mathrm{C}(10 \%$ para ambas as posições). $\mathrm{O}$ contrário foi observado nas folhas do ápice caulinar: o valor de PIR foi $13 \%$ a $100{ }^{\circ} \mathrm{C}$ e $50 \%$ a $4{ }^{\circ} \mathrm{C}$.

Quanto à porcentagem de danos (PD), os dados revelaram que os maiores danos (99\%) foram obtidos na temperatura de $100{ }^{\circ} \mathrm{C}$, em folhas intermediárias e basais, e $98 \%$ nas folhas apicais, enquanto que os menores valores de PIR (98\%) foram registrados para $4{ }^{\circ} \mathrm{C}$, nas posições intermediárias e basais, e $99 \%$ na posição apical do caule, portanto, resultados inversos.

Segundo Pimentel et al. (2002), uma menor PD irá indicar uma maior tolerância protoplasmática, o que reforça os dados obtidos. Além disso, neste trabalho foi possível constatar que as folhas intermediárias e basais foram caracterizadas como mais sensíveis aos tratamentos, uma vez que tiveram maiores integridades absoluta e relativa e um maior percentual de danos sob o tratamento de temperatura elevada.

Com relação à tolerância protoplasmática, o presente trabalho constatou valores maiores para a temperatura de $100{ }^{\circ} \mathrm{C}$. Esse dado pode ser confirmado em Silva (1976) e Paula et al. (1990), que afirmam que os menores valores de PD (com altos valores de PIA e PIR) refletem uma maior integridade da membrana na folha durante o dessecamento, devido, em parte, à menor atividade das enzimas hidrolíticas e/ou da composição de lipídios da membrana. Os resultados, obtidos nesta experimentação 
corroboram também os resultados de Paim (2002) no que diz respeito à baixa tolerância da aroeira-dosertão a período prolongado sob estresse hídrico.

\section{CONCLUSÕES}

- O déficit hídrico reduz a taxa fotossintética em plantas de aroeira-do-sertão.

- O déficit hídrico promove o incremento do conteúdo relativo de água nas folhas nas posições basal, intermediária e apical do caule, devido à sua relação direta com o processo de transpiração, condutância estomática e com o crescimento da lâmina foliar.

- As folhas de aroeira-do-sertão apresentam maior tolerância protoplasmática quando submetidas a temperatura elevada, principalmente nas folhas de posição intermediária no caule, cujo crescimento está completo apesar de ainda juvenis.

\section{REFERÊNCIAS}

AMORIM, S. M. C. de; PAIM, A. C. B.; SILVA, M. G. Estudo ecofisiológico sobre endomicorrizas:o efeito do déficit hídrico sobre a colonização endomicorrízica em duas espécies vegetais típicas da região semi-árida do Nordeste. Biotecnologia Ciência \& Desenvolvimento, Brasília, DF, v. 7, n. 33, p. 23-26, jul./dez. 2004.

BARBOSA, Z. Efeito do fósforo e do zinco na nutrição e crescimento de Myracrodruon urundeuva FR.ALL (aroeira do sertão). 105 p. Dissertação (Mestrado em Agronomia) - Universidade Federal de Lavras, Lavras, 1994.

BARRS, H. D.; P. E. WEATHERLEY. A re-Examination of the relative turgidity technique for estimating water deficits in leaves. Australian Journal of Biological Sciences, Melbourne, v. 15, p. 413428, 1962.

DEXTER, S. T.; TOTTINHAM, W. E.; GRABER, L. F. Investigations of the hardiness of plants by measurement of electrical conductivity. Plant Physiology, Minneapolis , v. 7, p. 63-78, 1932.

FIGUEIRÔA, J. M. de; BARBOSA, D. C. de A.; SIMABUKUR, E. A. Crescimento de plantas jovens de Myracrodruon urundeuva Allemão (Anacardiaceae) sob diferentes regimes hídricos. Acta Botanica Brasilica. Porto Alegr, v. 18, n. 3, p. 573-580, 2004.

KIKUZAWA, K. A cost-benefit analysis of leaf habit and leaf longevity of trees and their geographical pattern. American Naturalist, Chicago, v. 138, p.1250-1263, 1991.

KITAJIMA, K.; MULKEY, S. S.; SAMANIEGO, M.; WRIGHT, S. J. Decline of photosynthetic capacity with leaf age and position in two tropical pioneer tree species. American Journal of Botany, Columbus, v. 89, p. 1925-1932, 2002.

LARCHER, W. Ecofisiologia vegetal. São Paulo: Rima, 2006., 531 p.

LEONARDIS, R. F. J.; DIMITRI, J.. Livro del árbol: essencias forestales indígenas de la Argentina de aplicación ornamental. Buenos Aires: Celulosa Argentina. 1976.

MANSUR, R. J. C. N.; BARBOSA, D. C. A. Comportamento fisiológico em plantas jovens de quatro espécies lenhosas da caatinga submetidas a dois ciclos de estresse hídrico. Phyton, Buenos Aires, n. 68, p. $97-106,2000$.

MEDEIROS, A. C. S. Comportamento fisiológico, conservação de germoplasma a longo prazo e previsão de longevidade de sementes de aroeira (Astronium urundeuva). 127 p. Tese (Doutorado em Agronomia) - Universidade Estadual Paulista Júlio de Mesquita Filho, Jaboticabal, 1996.

MELLONI, R.; SILVA, F. A. de M.; CARVALHO, J. G. de. 2000. Cálcio, magnésio e potássio como amenizadores dos efeitos da salinidade sobre a nutrição mineral e o crescimento de mudas de aroeira (Myracrodruon urundeuva). Cerne, Lavras, v. 6, n. 2, p. 35-40, 2000. 
MONTEIRO DE PAULA, F.; PHAM THI, A. T.; VIEIRA DA SILVA, J.; JUSTIN, A. M.; DEMANDRE, C.; MAZLIAK, P. Effects of water stress on the molecular species composition of polar lipids from Vigna unguiculata L. leaves. Plant Science, Clare, n. 66, p. 185-193, 1990.

NOGUEIRA, R. J. M. C.; MORAES, J. A. P. V.; BURITY, H. A.; BEZERRA NETO, E. Alterações na resistência à difusão de vapor das folhas e relações hídricas em aceroleiras submetidas a déficit de água. Revista Brasileira de Fisiologia Vegetal, londrina, v. 13, n. 1, p. 75-87, 2001.

NOGUEIRA, R. J. M. C.; BARBOSA, D. C. A.; MORAES, J. A. P. V. Trocas gasosas e relações hídricas em plantas jovens envasadas de três espécies da caatinga, submetidas a deficiência de água. Phyton, Buenos aires, v. 62, n. 1/2, p. 37- 46, 1998.

NOGUEIRA, R. J. M. C.; BURITY, H. A.; MORAES, J. A. P. V. Transpiração e potencial hídrico foliar em aceroleiras (Malpighia emarginata DC) cultivadas na zona semi-árida de Pernambuco. Revista Científica Rural, Bagé, v. 3, n. 2, p. 75-81,1998.

NOGUEIRA, R. J. M. C.; MELO FILHO, P. A.; ARAÚJO, E. L. Expressões ecofisiológicas de germoplasma de Harconia speciosa Gomes cultivada no litoral de Pernambuco. Ciência Rural, Santa Maria, v. 29, n. 4, p. 731-732, 1999.

PAIM, A. C. B. Avaliação do efeito do estresse hídrico na estrutura, ecofisiologia e na bioquímica de plântulas Myracrodruon urundeuva Fr. All. (Anacardiaceae). 80 p. Dissertação (Mestrado) Universidade Estadual de Feira de Santana, Feira de Santana, 2002.

PIMENTEL, C.; SARR, B.; DIOUF, O.; ABBOUD, A. C. S.; ROY-MACULEY, H. Tolerância Protoplasmática foliar à seca, em dois genótipos de caupi cultivadas em campo. Revista Universidade Rural. Série Ciências da Vida. Rio de Janeiro, v. 22, n. 1, p. 07-14, 2002.

QUEIROZ, C. G. S.; GRACIA, Q. S.; LEMOS FILHO, J. P. Atividade fotossintética e peroxidação de lipídios de membrana em plantas de aroeira-do-sertão sob estresse hídrico e após reidratação. Brazilian Journal of Plant Physiology, Piracicaba, v. 14, n. 1, p. 59-63, 2002.

ROY-MACAULEY, H.; ZUILY-FODIL, Y.; KIDRIC, M.; PHAM THI, A. T.; VIEIRA DA SILVA, J. Effect of drought stress on proteolytic activities in Phaseolus and Vigna leaves from sensitive and resistant plants. Physiologia Plantarum, Copenhagen, v. 85, p. 90-96, 1992.

SILVA, E. C. da; MANSUR, R. J. C. N.; AZEVEDO NETO, A. D. de; SANTOS, V. F. dos. Comportamento estomático e potencial da água da folha em três espécies lenhosas cultivadas sob estresse hídrico. Acta Botânica Brasílica, Porto Alegre, v. 17, n. 2, 2003.

VASQUEZ-TELLO, A.; ZUILY-FODIL, Y.; PHAM THI, A. T.; VIEIRA DA SILVA, J. Electrolyte and Pi leakages and soluble sugar content as physiological tests for screening resistance to water stress in Phaseolus and Vigna species. Journal of Experimental Botany, Oxford, v. 41, p. 827-32, 1990.

VIEIRA da SILVA, J. Water stress, ultrastructure and enzymatic activity. In: Ecological studies 19. analysis and synthesis. LANGE, O. L., L.; KAPPEN, E.; SCHULZE, D. (Eds.). Berlin: Springer-Verlag, 1976. p. 207-224. 